\title{
English on Korean television
}

\author{
JAMIE SHINHEE LEE*
}

\begin{abstract}
This study discusses verbal humor in entertainment media and examines polarizing representations of English on Korean television. English is a source of stress as well as a medium of humor. Language anxiety about English speaking skills is frequently focalized and viewed as a personal challenge by Korean celebrities, but they often transform their linguistic 'complex' into humorous talk. This study argues that using English, possibly the most revered and yet the most feared language in Korea, in humor is sociolinguistically significant, embodying attitudinal, emotional, and experiential ambivalence about English in globalization-minded contemporary Korea. The findings of the study suggest that generationconscious ageism regarding English proficiency typically characterizes senior citizens as sociolinguistically underperforming, which sometimes forces them to be in a vulnerable position both in familial and social contexts. Increasing use of English on Korean television divides bilingual viewers and monolingual viewers and whether one can be entertained and humored by television programs may become another Englishrelated stratification variable in Korea.
\end{abstract}

\section{INTRODUCTION}

English is used increasingly in verbal humor in Korean entertainment media, and a common theme is English speaking skills and language anxiety. Using English in Korean humor is sociolinguistically consequential considering that the English language signifies attitudinal and emotional duality - coexistence of devotion or even fanaticism and odium - for many Koreans. English is possibly the most revered and at the same time the most feared foreign language in contemporary Korea (Lee 2007), and ambivalent stances exist both individually and collectively as a society (Lee 2012). Koreans with education beyond high school have some familiarity with English, but many readily admit that they have 'a complex' about English - a Korean way of saying that they do not feel confident about the English language. Linguistic insecurity about English, particularly spoken English, can be a source of anxiety yet also a drive for improving English communication skills. It is commonly noted in contemporary Korean society that English proficiency affects academic and professional success and the importance of speaking English is bolstered by the idea of globalization (Lee 2011). Reactions to globalization are generally positive due to its economic appeal, but responses to increasing pressure to speak 'better' English are divided. Conflicting and contradictory needs and desires often co-habit the same local linguistic and metalinguistic space.

Media, particularly television, showcases these differing sometimes clashing ideologies of the English language. Park (2009) notes that the hegemony of English is faced with competing ideologies of appropriation and resistance, contending ideologies expressed

\footnotetext{
*Dept. of Language, Culture, and Communication; University of Michigan-Dearborn; 4901 Evergreen Road; Dearborn MI 48104; USA. E-mail: jamilee@umich.edu
} 
routinely in the media. The present study discusses seemingly conflicting and polarizing representations of English use in entertainment media and argues that these contending ideologies come from the same source-English language anxiety. Most studies on language anxiety are about classroom settings and academic contexts "(see, e.g. Horwitz et al. 1986; Daly 1991; Cheng and Erben 2012). This study, however, addresses English language anxiety in a non-academic setting - humorous discourse in entertainment media - expanding the empirical scope of research. It will be argued that English language anxiety discursively framed through humor helps to turn painful personal stories into effective linguistic devices forming a potentially powerful bond between the narrator and the audience. When entertaining viewers is the main object of a television program, uncomfortable experiences caused by language anxiety and foreign language stress are no longer unpleasant conversation topics. Rather, they provide amusing, cathartic narratives when shared with sympathetic listeners.

\section{ENGLISH AND KOREAN TELEVISION}

Korean stars are praised for their 'good' English. Those speaking 'poor' English suffer from language anxiety. For example, the actor Lee Byung Hun, who has risen as a global star after staring in the Hollywood Movie G.I. Joe: The Rise of Cobra, describes the stress and tension caused by English while shooting the movie:

\footnotetext{
Whenever my awkward intonation was criticized on the set, I just drew a blank. I had to concentrate on intonation and pronunciation so much that it was difficult for me to focus just on acting. My head hurt when I had to use English (shaking head). ${ }^{1}$ We had a press tour for G.I. Joe in Japan not long ago. They interviewed me in English. Japanese reporters did not use English, but there were reporters from Hong Kong, Singapore, and the Philippines, so I used English. I am sure a lot of what I said was edited out because it didn't make sense (laughing). ${ }^{2}$ (Lee 2009)
}

Celebrities' inadequate English, however, does not always negatively affect their careers since quick-witted ones use their 'misery' as the material for humor, which will be shown in this paper. Stressful situations caused by inability to speak English seem to provide excellent content for humorous narratives, especially self-effacing humor. English-related anecdotes are often unpleasant memories for Korean celebrities, but their challenging situations are perceived as amusing by viewers since these stories are others' stories but are yet recognized as relatable and can be easily imagined as probable. English-related humor in Korean entertainment media is often performed deliberately. Hilarity, however, also emerges when performers do not intend their English to be comical but their use of 'Korean-style' English elicits laughter from panelists and studio audience.

Characters using English in Korean television dramas are generally polarized into two types: educated successful professionals or undereducated and unsophisticated middle aged or senior citizens aspiring to fit in or promote their social standings, albeit temporarily. Script writers' use of English to portray a particular character is carefully planned as actors are expected to follow the script closely, not having the flexibility or the liberty of changing their lines. Television talk shows and reality shows have scripts too, but these scripts are much more flexible; they generally list questions to be asked and topics to be discussed but do not necessarily dictate exactly what guests should say. Talk show and reality show participants can act and speak rather freely; their reactions and responses are not as 
carefully planned as television dramas. Thus improvised witty remarks and adlibs are quite common. This, of course, does not mean that everything we see on these shows is always natural and real. Unless live, most shows are subject to a careful editing process, which mostly involves deleting uninteresting comments and scenes. In fact, editing decisions to determine whether something is worthy of public showing reveals sociocultural ideologies of entertainment. The fact that narratives about English language anxiety and 'Korean style' English expressions appear in Korean shows demonstrates that producers are aware of viewer interest in the use of English by Korean celebrities.

\section{HUMOR AND BILINGUALISM}

Humor is generally appreciated in human communication, both spoken and written. Face to face interaction can be made pleasant through humor and 'staged' conversations on television and in film become amusing and entertaining through humor. Humor is an integral part of entertainment and, arguably, one of the most important factors for the success and popularity of television programs. As many physical comedies and slapsticks attest, humor can be performed successfully by means of non-verbal behavior but verbal humor is expressed mostly through one's native language. For example, American comics use English to construct humorous discourse. They may imitate someone else's dialect or accent or exaggerate their own accent and dialect, but comic relief is generally achieved by some form of English, either standard or accented or sometimes both. It is not so common that a monolingual comedian whose mother tongue is English delivers funny lines in a language other than English. Korean television celebrities, on the other hand, do use foreign languages to create humor, typically Chinese, Japanese, and English. When Chinese and Japanese are used in Korean humor, they do not carry semantic content. Nonce words and nonexistent sentences are uttered by Korean celebrities in 'fake' Chinese and Japanese because they do not actually know these languages. In contrast, when English is used in verbal humor, it contributes significantly to the overall semantic make up of a discourse, since Korean humorists have some knowledge of English. However, this does not necessarily mean that they are fluent in English or use English regularly when not performing on television. In both carefully scripted (e.g. code-approximation in Lee 2007) and improvised discourses on television, Korean celebrities' verbal humor highlights and often exaggerates English deficiencies. 'Korean-style' English widely known as 'Konglish' is advertently or inadvertently used, creating a comical persona or situation. Whether this type of humor is appreciated or not depends on viewers' English proficiency, consequently perpetuating the division between Korean-English bilinguals and Korean monolinguals.

Bilinguals' ability to switch back and forth between two languages is generally viewed as positive. Corbett (1991) observes that balanced bilinguals are flexible thinkers and are generally good at noticing similarities and incongruities in communication, which contributes to their creativity. Haugen (1986:119) asserts that bilinguals 'have two instruments for living, and they are in the happy position that they can switch from one to the other, that they can even mix them and switch within a single sentence, and that they can be two different persons and live in two different worlds when one of these becomes too boring or troublesome.' Among bilinguals' characteristics studied in linguistic research, humor has not been a main focus. In fact, some scholars have voiced concern over scanty research on humorous narratives in conversation (Norrick 2004; Norrick and Chiaro 2009) and particularly on L2 humor (Bell 2007). 
Although not extensive, studies on bilingual humor are available (see e.g. Haugen 1986; Leeds 1992; Alaba 1992; Siegel 1995; Vaid 2006; Lee 2007; Jin and Wang 2012). These studies are generally concerned with deviation, phonetic similarity, or self-deprecation. Zhao (1994:1) draws on deviation theory to explain humor and argues that 'playful deviations are the core of humor production and enjoyment.' Jin and Wang (2012) also contend that the gap between the maximal relevance expectation and the optimal relevance creates humor. Linguistically, three deviations are reported to create humor: phonological, morphological and syntactic deviations (Zhao 1994).

Most studies on bilingual humor so far seem somewhat narrowly focused on pronunciation. Esar argues that 'the leading techniques in English humor are phonetic' (cited in Zhao 1994:70). Phonetic sameness creates amusing ambiguities (Zhao 1994) and puns are good examples of that. Both code-ambiguation in Moody and Matsumoto (2003) and code-approximation in Lee (2007) refer to similar points. Analyzing letters written by Norwegian-American informants, Haugen (1986:116) provides examples of bilingual humor capitalizing on phonological similarities between English and Norwegian. Bilingual humor examples in Haugen's research include homophonous words such as river (for røver 'robber'), barn (for 'child'), and grease (gris 'pig'). Jin and Wang's (2012: 45) analysis of China born comedian Joe Wong's verbal humor also contains homophonous puns such as who (for Chinese last name $\mathrm{Hu}$ ) for example, 'Good evening, everyone. My name is Joe Wong. But to most people, I am known as 'Who?'(Hu?). According to Zhao (1994:69), 'phonological deviations occur when the funniness comes from the manipulation of the phonological elements of sound.'

Another topic frequently addressed in humor research is self-deprecation. Especially women are reported to use self-deprecating humor (Holmes and Schnurr 2005, Bell 2007). Self-deprecation is also commonly utilized in bilingual humor in this study. Ross (1998) notes that humor is achieved when there is an element of surprise, but verbal humor related to English on Korean television has very little element of surprise. Rather, the ideology of self-deprecation, a term introduced by Park (2009), is mostly expected and fairly prevalent. Overgeneralizing Koreans' inability to speak English is not a taboo; it is a subject regularly brought up by Korean celebrities in anecdotes about language-related stress. Although the idea that Koreans do not speak English well is an old one, it has recently become more perceptually and experientially salient partly due to increasing opportunities of international travel and exposure to English language-medium pop culture products. Also, the notion of 'creating global Koreans' hinges primarily on English communication skills. As the pressure of speaking English is mounting, the gap between the ideal of speaking English fluently and the reality of not being able to do it satisfactorily may seem widening to many Koreans (Lee 2011).

Self-deprecation in entertainment media is not necessarily viewed as negative. In fact, Bell (2007:203) notes that self-mocking narratives in humor serve some positive functions, arguing that 'laughing at one's own foibles demonstrates a kind of strength and confidence, as personal shortcomings are presented publicly. At the same time, doing so may also offer protection from the censure of others.' Bell's (2007) discussion of non-native speakers' feeling inadequate regarding L2 humor provides insights relevant to language anxiety addressed in the present study. Both Bell's study and the present study deal with humor and non-native speakers of English, but these studies discuss different aspects of L2 humor. Bell's study focuses on humorous narratives in personal communication, whereas the present study examines humor featured in performance-conscious television programs. 
The humorous narratives in Bell's study were told in English in interactions with native speakers, and these narratives were not about the English language. On the other hand, the funny stories presented in this study were specifically about the English language and English-related difficulties. These humorous stories were told partially in English, and their addressees were Korean speaking audience members in the studio, not native speakers of English.

Bell (2007: 221) notes that non-nativeness contributes to the notion that ESL speakers are not full participants in communication and further argues that 'telling a self-deprecating story might be risky from an already perilous social position' The view that self-deprecating humor can be a precarious move for non-native speakers of English may be a valid concern when it occurs in linguistically asymmetrical contexts such as a conversation between a native speaker and a non-native speaker. However, self-mocking humor featured in the present study seems to serve as a discourse mechanism promoting camaraderie among non-native speakers of English who feel the same pain. Pain can be turned into laughter when showcased in a performance. In his discussion of stand-up comics, MacRury (2012: 189) observes:

On stage, the background noise of everyday pain and existential dread is turned and tuned by the humourist for his audience and by them and thus evokes both loss and its overcoming: laughter, smiling, a shared shrug; the silently intoned underscore that says, 'Always look at the bright side of life.' Internally, imagined-memorial parental protection undermines and distances everyday distresses, insults and their objects. 'Look at the big picture. Life's OK, we're in this together.'

Similarly, the Korean celebrities in this study present their humbling experiences in selfmocking narratives. In so doing, they seem to alleviate language stress and invite audience members to commiserate with them.

\section{DATA}

The shows discussed in the study were selected primarily because their ratings were favorable and major newspapers reported them to be successful shows. Various genres (e.g. drama, reality show, talk show, quiz show, etc.) and all major Korean networks, nationally viewed without individual cable subscriptions, are included in the data. These shows were regularly viewed by the researcher between May 2009 and January 2010 generally on a weekly basis and humorous English expressions presented in these shows were documented in an observation log along with comments on contexts and characters. The relevant interactions were first transcribed in Korean and subsequently transliterated and translated into English. ${ }^{3}$

Talk shows that are popular in Korea these days tend to feature celebrity guests relating interesting experiences and hilarious anecdotes. Most reality shows highlight celebrities competing in a game or challenge. For example, Namcauy Cakyek ('Men's qualifications') features seven celebrities (four comedians/show hosts, a rocker, and two television actors/models) in various age groups (20s to $50 \mathrm{~s}$ ) accomplishing 'a mission' each week out of '101 things men should try before they die,' which is in essence a dream bucket list for most men. On the other hand, Mwuhan Girls ('Limitless Girls') is a female version of that, staring six women (two show hosts, two comediennes, and two singers) competing in a different challenge each week. Some of these mission-oriented shows present 
Table 1. Television programs

\begin{tabular}{|c|c|c|}
\hline Title & Network & Genre \\
\hline $\begin{array}{l}\text { Posek Pipimpap } \\
\text { 'Mixed Gemstones' }\end{array}$ & MBC TV & Drama \\
\hline $\begin{array}{l}\text { Twu Anay } \\
\text { 'Two Wives' }\end{array}$ & SBS TV & Drama \\
\hline $\begin{array}{l}\text { Kongpwuui Shin } \\
\text { 'The Academic Master' }\end{array}$ & KBS 2 TV & Drama \\
\hline Happy Together & KBS 2TV & Talk show \\
\hline $\begin{array}{l}\text { Nolewa } \\
\text { 'Come and Visit' }\end{array}$ & MBC TV & Talk show \\
\hline $\begin{array}{l}\text { Star Pwu Pwu Show } \\
\text { 'Star Couples Show' }\end{array}$ & SBS TV & Talk show \\
\hline $\begin{array}{l}\text { Seypakhwi } \\
\text { 'The Quiz Changing the World' }\end{array}$ & MBC TV & Talk/quiz show \\
\hline $\begin{array}{l}\text { Wuli Kyelhonhaysseyo } \\
\text { 'We Got Married' }\end{array}$ & MBC TV & Reality show \\
\hline $\begin{array}{l}\text { Gold Miss-ka Kanta } \\
\text { 'Go Gold Miss!' }\end{array}$ & MBC TV & Reality show \\
\hline $\begin{array}{l}\text { Namjauy Cakyek } \\
\text { 'Men's Qualifications' }\end{array}$ & KBS 2TV & Reality show \\
\hline $\begin{array}{l}\text { Mwuhan Girls } \\
\text { 'Limitless Girls' }\end{array}$ & MBC TV & Reality show \\
\hline
\end{tabular}

opportunities for participants to use English. For example, a weekly dating show called Gold Miss-ka kanta 'Go Gold Miss'4 arranges a blind date for one of the six single women in their mid to late 30s. Sometimes their dates are Koreans who are educated or raised in English-speaking countries. Talk show guests often share humorous anecdotes caused by their inability to communicate in English well.

\section{Ageism and english}

Park (2003: 149) observes that 'inability in English,' 'bad English,' 'hyper-Koreanized pronunciation' are topicalized in Korean-English humor. Although the predominant rhetoric is that Koreans are poor speakers of English, some populations are stereotypically more harshly characterized as 'incompetent' in English than others, a fact not addressed in earlier research. In particular, senior citizens and middle-aged housewives with no careers are routinely typecast as the English unknowing in Korean entertainment media. If they use English, they are either criticized for posing as someone that they are not or their 'bad' English is explicitly commented on and ridiculed.

A case in point is presented in excerpt (1). The interaction features two senior citizens in their late 70s who are in-laws and do not get along. Pakjo, portrayed as a materialistic and superficial shopaholic, considers herself to be much more sophisticated than her inlaw, Myungja. In contrast, Myungja is supposed to be practical and down-to-earth. She is frugal and content with her modest lifestyle. In this particular episode, Pakjo attempts to communicate in English with an American tenant named Kyle, who is renting a room in her daughter's house while studying to be a Buddhist monk. Kyle speaks Korean well, but 
Pakjo does not know that because they just met for the first time.

(1) Pakjo: How are you?

Kyle: Fine, thank you.

Pakjo: What your name?

Kyle: Kyle Huntington

Pakjo: Yes, yes, my name is Pakjo. Grandma Kyulmyungja name Kyulmyungja

(pointing to her in-law, Myungja)

Pakjo: Na yenge cal haci? (looking at Myungja)

'Don't you think my English is good?'

Myungja: Neya ipulo hanunken ta calhaci.

'Anything you do with your mouth, you do well.'

(Posekpipippap 'Mixed Gemstones' aired on 9 September 2009)

Pakjo's English consists of simple greetings and contains syntactic features such as copula deletion (e.g. 'what your name?') and absence of the possessive morpheme - 's (e.g. 'Grandma name'). The word grandma is a loan translation of the Korean counterpart halmeni, which literally means 'grandmother' but can also refer to a female senior citizen. Pakjo boasts of her English and hopes to be complimented by Myungja, but Myungja trivializes Pakjo's English speaking skills and mockingly criticizes Pakjo's garrulity.

Elderly Koreans are widely believed to possess very little or no knowledge of English, whereas young children are reported to speak better English than previous generations mainly because of their early exposure to spoken English in kindergarten. It is common that English proficiency is discursively framed as variable according to age groups and generations. In excerpt (2), comedian Lee Hyukjae, one of the guests on Happy Together, describes his father's undignified experience of not knowing simple English words when quizzed by his grandson. The grandson's English proficiency gives him the upper hand in his relationship with his grandfather, which would be inconceivable if the interaction were carried out exclusively in Korean. Hyukjae is impressed with how much English his son is learning in kindergarten and reveals how much his father suffers because he fails to understand and speak very basic English. The panelists are impressed with the level of English Korean children are exposed to these days. Hyukjae describes what level of English is being taught in his son's kindergarten and stresses the importance of being familiar with colloquial English.

(2) Hyukjae: Yocum yenge tane oywusyeya toyyo. Mos oywulttaynun cheypelina honnacimalko

'You need to be keen on building English vocabulary these days. Otherwise, you may be punished or scolded.'

Get out of here. Sensayngnimi native sensayngnimi sikhinapwa.

'(My son says) "Get out of here." His teacher is a native speaker of

English. I get the feeling that his teacher says it (when his students fail to memorize vocabulary).'

Panelists: Ah.

'Oh!'

Hyukjae: Cipeyse halapecika kukel mos oywumyen Get out of here. 


\section{words.'}

'My son yelled, "Get out of here" when my father could not memorize English

Elevator yephey panphalchalimulo sekyeyseyyo. Waykulenyako hamyen

Get out of here tanghasyesstakwu. (studio audiences and panelists laughing)

'I saw my father standing outside the apartment next to the elevator only with his short-sleeved shirt on (in November). I asked him why and he said that he was told to "get out of here.",

Inomuy casiktul eti halapecilul? Apecito kulehci.

'I said to my bratty kids, "How dare you mistreat your grandfather?" I also said to my father, "Dad, you too (are at fault).",

Apple, cat kulen katanhan cengto oywusici way ccochkyenaseyyo? Tulekapnita.

'(I said to my father) Apple, cat, these are easy words. You can memorize them.

Why would you be kicked out of the house because of that?'

Ya kackwuwa. Appaka polantusi oywecwulkkey. Refrigerator, nayngcangko spelling aseyyo? (He is asking the panel.)

'I said to my son, "Bring me a word list. I'll memorize it." Do you know

how to spell refrigerator?'

Jaesuk: Ney?

'Pardon?'

Bongsun: Nayngcangko yengelo mwelakwuyo?

'What did you say nayngcangko ('refrigerator') is in English?'

Hyukjae: Refrigerator.

Bongsun: Cheum tulepwasse. Cincca.

'Never heard it before. Really.'

Hyukjae: 74 seytoyn wuli apecikkey nayngcangko oywulako sikhyesstelakwuyo.

'As it turned out, my son told my 74-year-old father to memorize the word

refrigerator.'

Misun: Wulihako swucwuni tallayo.

'Young generations are certainly different from us.'

(Happy Together aired on 26 November 2009)

Misun's comment at the end robustly echoes 'the generation conscious discourse' voiced by Korean women regarding globalization and English in Lee (2009).

\section{English language anxiety}

Language anxiety is reported to be generally caused by concern for negative evaluation, communication angst, and test fear (Horwitz et al. 1986). Bailey et al. (2000: 474) report that 'foreign language anxiety is a complex phenomenon that occurs at each stage of the language learning process.' In their study of Chinese graduate students' language anxiety in the US, Cheng and Erben (2012) suggest that the length of stay in an English speaking country can lower language anxiety and art-related majors show the lowest language anxiety. Also, acculturation and gender are addressed as factors affecting language anxiety. Onwuegbuzie et al. (1999) discusses attributes of speakers with high language anxiety including age, level of academic achievement, overseas travel experiences, past language lessons, self-perceptions and expectations of academic competence, and self-image.

Use of 'Korean style' English in interaction with non-Koreans inadvertently leads to inappropriate discourse and resultant stress and anxiety. However, when a stressful anecdote 
is retold, it is transformed into an amusing incident, eliciting laughter from studio audiences and fellow talk show participants. When asked to share their 'caymi issnun episode' ('funny anecdote'), several celebrities explain difficulties they experienced while traveling or temporarily living outside Korea. The theme of this particular episode of the show was not English or English-related anxiety. While interviewing the guests of the show, the host hosts asked if the panelists had experienced something funny lately. In response, a panelist tells what he had to endure on an overseas trip, which is presented in excerpts (3) and (4).

On Star Pwu Pwu Show ('Star Couples Show'), comedian Kim Hansuk, reports an unfortunate incident he and his wife experienced on a trip to Thailand. He prefaces his narrative with the discourse of inadequacy in English competence. His wife became sick on the trip but he could not arrange much needed medical care in a timely fashion because of his inability to express himself fully in English. Before telling the story, Hansuk reiterates that he is unable to communicate in English, which he classifies as the 'well-known' fact. When his attempt to get help from the front desk failed, Hansuk decided to make matters into his own hands and called a taxi to go to the hospital.

(3) Hansuk: Cenun yenge moshanikka ... akkato malhayssciman yengeka antwaysscanhayo.

'I can't speak English... as I said earlier my English is impossible.'

Room serviceey selmyengul hayya toynuntey my wife ttukepta ${ }^{5}$ hot hot

'I had to explain my wife's condition to the room service... (I said) my wife

hot hot hot.'

What? (imitating the room service staff). My wife hot? (studio audiences and panelists are laughing.)

Yongman: Wulhwathongi thecyeyo ceycasini.

'I get so frustrated just listening to you.'

Hansuk: A mwelakwu? Tanghwanghanuntey yengenun antoycyo

'(I said) "What?" I was flustered and could not speak English.'

Seungshin: Help me! ${ }^{6}$

Hansuk: Nacwungey ku help me-to molunun keeyyo. Nemwu tanghwanghanikka.

'Much later. Even that simple help me didn't occur to me. I was at my wit's end.'

Eyi kwulikwu kkunhkonase iltan cipsalamul epesseyo. Taxi-lul capathasseyo.

'Uh, I just hung up and carried my wife on my back and got a cab.'

Hospital hospital nemwu kuphanikka pyengwen tochakhayse tulchyeepko

'I yelled hospital hospital because I was desperate. I carried my wife on my back

and arrived at the hospital.'

Ungkupsiley ttwie twule kankeeyyo. Mak doctor doctor oychinikka.

'I ran into the emergency room. I shouted, Doctor Doctor!'

Heyeuni: Yenge manhi haney!

'You speak quite a bit of English!'

(Star Pwupwu Show ‘Star Couple Show' aired on 4 December 2009)

As clearly indicated in his narrative, Hansuk was not aware that 'my wife hot' did not mean that she had a fever, which was what he intended to mean at the time. There is no indication in the data that he understands that the word hot has a sexual connotation. Heyeuni's remark on Hansuk's English ('You speak quite a bit of English!') suggests that she evaluates that Hansuk's English is better than he leads people to believe, focusing on 
the quantity not the quality or overall success of his English communication. She is the only panelist that offers any positive comment on his English. Being the oldest panelist and unable to speak English herself seems to have contributed to her 'generous' assessment of Hansuk's English skills. In contrast, Seungshin, who is in her 30s, without hesitation offered a much needed expression, 'Help me,' to Hansuk, indicating that a simple phrase could have solved his communication problem. Two panelists from different generations respond contrastively to Hansuk's English: the older generation somewhat enviously recognizing his 'competent' English versus the younger generation noticing his inadequate English. This is an illustrative example of perceptual ageism regarding English, discussed earlier in the paper. Hansuk's remark that he could not remember even 'help me' suggests that it is a common phrase most Koreans can think of in that situation but he failed to do so.

Inability to speak English appears to trigger strong emotional reactions including selfhatred (e.g. 'I hated myself'), frustration (e.g. 'I was very irritated'), and anger (e.g. 'I was about to explode'), which were reiterated by Hansuk in excerpt (4) below. His miscommunication continues at the hospital. He reacted violently to the doctor, throwing an ice pack because he thought the doctor misunderstood him and provided only a bare minimum treatment. Using an ice pack is commonly performed first aid procedure in an average Korean household when a family member develops a fever. His expectation that the hospital should provide a much more technical medical treatment than simply applying an icepack was not satisfied, and as a result he became extremely angry.

(4) Hansuk: Naycasini cengmal silhesseyo.

Yongman: Ya!

'I really hated myself.'

'You!'

Hansuk: Yengelul nemwu moshanikka.

'Because my English was so bad.'

Wonhee: Taptaphaci!

'It must have been so frustrating!'

Hansuk: My wife hot, hot, hot Kuntey uysaka nay sanghwangul ponikka. It's cold? It's cold?'7

'(I said), My wife hot, hot, hot. Then the doctor assessed the situation and said,

No, no, no. It's hot, hot, hot. Cold? Hot! Ccacungi simhacanhayo. (panelists laughing)

'(I said), No, no, no. It's hot, hot, hot. The doctor asked, Cold? (I screamed)

Hot! I was very irritated.'

Hansuk: Amwukesto anhako elumul ollyenohko issnun keeyyo.

'The only thing he did was put ice on her.'

Yongman: Pokcang thecicyo.

'You must have been really upset.'

Hansuk: Pokcang thecicyo! Hwaka hwaknase ikestuli elum ike hana ttak ollyenwa?

'I was about to explode! I was so angry. What the heck! Only an ice pack?'

Elmana hwaka nayo. Nayka elumul hwak tencyesseyo.

'You can imagine how angry I was. So I threw the ice pack.'

Yengelo hwalul nayya haltheyntey tenciko kekikkaci. (studio audiences laughing)

'I should have expressed my anger in English . . . but I just threw the ice pack and had to stop there.'

(Star Pwupwu Show 'Star Couple Show' aired on 4 December 2009) 
The panelists laugh when Hansuk's 'hot' and the doctor's 'cold' are contrastively presented, comically contextualizing the confusing situation. When Hansuk admits that he could not show full-blown anger because of his limited English, the studio audiences burst into laughter. The situation was extremely upsetting for him, but his self-proclaimed 'poor English' caused Hansuk to fail to calmly verbalize his anger and frustration in English. He had to rely exclusively on non-verbal means of communication at the end. This example shows that English is a source of stress but also a medium of humor, highlighting polarizing and contradicting representations of English in Korean entertainment media.

Additional examples of polarization of English are presented in excerpts (5) through (7). Comedian Kim Junglyul explains how frustrating it was to be treated unfairly because of his limited English but at the same time he also shows how liberating it was to use English to retaliate against injustice. Similar to Hansuk in excerpt (3), Junglyul in excerpt (5) prefaces his storytelling by emphasizing the stress caused by his low English proficiency.

(5) Junglyul: Eneka antwaymyen stress-ka pothongi anipnita.

'Language-related stress can be quite unbearable.'

I mikwukey cheumey tochakhaykaciko wulinala tampaykapsun I kakeyna

ce kakeyna ta ttokathcanhayo?

'This happened soon after I arrived in the US. In Korea, the price of a pack of cigarettes is fixed, isn't it? It doesn't matter where you buy it. We pay the same price.'

Panelists: Ney.

'Yes.'

Junglyul: Nan kulehkeyman sayngkakhako kan keya. Kulenchwul alasse. 4pwul 25 cent cwun alko.

'That's just what I thought. I thought it was $\$ 4.25$ everywhere in the US.'

Taluntey eti oysikhale nakasstaka grocery-ey kase incey tampay twukapman talako kulaysseyo.

'I went out to dinner in a new neighborhood. I went to a grocery store to buy two packs of cigarettes.'

Yejin: Kukel mwelako kulayyo?

'How do you say that in English?'

Junglyul: (Somewhat hesitant) ${ }^{8} \mathrm{Um}$. . . give me ... two cigarettes ... two box. Waykulay?

(studio audiences are laughing)

'Um ... give me ... two cigarettes ... two box. Why are you doing this to me?'

Yejin: (laughing)

Junglyul: Kunyang kamanhi ttek tusye hei cham nayka malul hanuntey way ccala? (looking at Yejin)

'Why don't you just keep eating rice cakes? Why are you interrupting me when I talk?'

(Seypakwi 'The Quiz Show Changing the World' aired on 5 December 2009)

When Junglyul tells a story in Korean, one of the panelists, Yejin, asks him to repeat his utterance in English. She seems genuinely curious to know how to say Tampay twu kap cwuseyyo ('Can I get two packs of cigarettes please?') in English. Junglyul, however, perceives her question as a challenge to test his English skills and becomes very defensive 
and criticizes her for giving him a hard time and ultimately embarrasses her by 'politely' telling her to 'shut up' ('Keep eating your rice cakes.'). This is a revealing example of how one's English proficiency can become a source of mockery and envy, showing that the discourse about one's own and others' English occurs commonly in conversation. Junglyul continues to describe what happened between a supermarket cashier and himself and how an unpleasant incident, triggered by an argument over the price of a pack of cigarettes, made him feel vulnerable. When Junglyul was verbally assaulted for changing his mind about the number of packs he wanted to buy, he was upset but felt linguistically inadequate to challenge the cashier, so at first he could not protest against the injustice done to him. However, when the cashier's verbal attacks escalated into swearwords, Junglyul used English curse words to fight back.

(6) Junglyul: Tampaykapsi nemwu pissankeya kulayse hana mwullyesse.

'It was much more expensive than I expected, so I returned one pack.'

I hukin cemweni hwakanase yengelo yokulhanunkeya. $F$ ! $F$-lo sicakhanun yokisscanha.

'Then this African-American cashier got angry and started cursing at me. You know, the curse starting with an f!'

Studio audience: E e e (in disbelief and in a disapproving tone)

'Uh.'

Junglyul: Ya! Ike nayka way yokul mekci? Twukap tala hankap tallanuntey kaman issepwa.

'Wow! I thought to myself, "Wait a minute. Why am I being cursed at?" I simply said I only needed one pack, not two.'

What did you say? Iyangpani nwunto kheyo! $F_{--}$you!

'I said, 'What did you say?' This guy had big eyes. ${ }^{9}$ He said,'F____you!' ,

Kulayse nato $F_{Z_{-}}$you kathi haysse. Mikwuk yokun pyello epscanhayo.

'So I also said, $F_{-}{ }_{-} y o u$. There aren't that many swear words in English.'

Son... God ... (excited) teisang malhalkey epse (anun yenge yoki pataknase)

(studio audiences and panelists laughing hysterically)

'Son (of a bitch) and God (damn). After these two I ran out of English swear words.' (Seypakwi 'The Quiz Show Changing the World' aired on 5 December 2009)

Junglyul continues to explain that his emotional distress was so severe that he could not sleep that night.]

(7) Junglyul: Mak soliciluko ssawunikka Hey you. Call the police. Shut the mouth.

'Because I was yelling at the top of my lungs and arguing, he said, "Hey you. (I'll) call the police if you don't shut up."'

Call the police. Hanikka kepi nanunkeya. Kaman issesse.

'When I heard him say Call the police, I got scared. So I became silent.'

Kulayse ccochkyenasseyo kekise. Kulentey cipey kase camul canuntey

'Then I got kicked out of that place. When I went home and tried to get some sleep that night.'

Cami anonunkeya yeli patakaciko.

'I couldn't go to sleep because I was still fuming over the incident.'

Hwijae: Ekwulhako pwunhaci! 
'I bet you thought it was infuriating and unfair!'

Junglyul: Kulayse ku taumnal tasi chacakasse.

'So I went back the following day.'

Mwunul yelko kuaneyse tulekase ttetulko hamyen yengeppanghaylapnita.

'I had heard that I would be arrested for a public misdemeanor and obstruction

of business if I yelled inside the store.'

Studio audiences: $A$ !

'Oh, I see!'

Junglyul: Kulayse chwulipmwunul ilehkey yelko Hey you! Remember me yesterday?

'So I opened the door like this and yelled from outside, Hey you! Do you

remember me from yesterday?'

F . . ! Son ...! God ... and ssakaci ('jerk') (panelists laughing hysterically)

Eyi kuliko ttaktatko kuliko cokum isstaka Hey you, you remember me?

'And then I closed the door and waited a little and then (opened the door again) and said, Hey you, you remember me?'

Son ... God... anun yenge yoki teisang malhalkey epse.

'Son (of a bitch) and God (damn). After these two I ran out of English swear

words.' (panelists laughing)

Kulayse hankwukmallotaka ilen ssakaci . . changca ppaykaciko cwulnemki

haypelilkkapota.

'So I started swearing in Korean. I said, ilen ssakaci ('jerk'). I want to take your

intestines out and jump rope with them'

Ccokaypelye ikel nelepelye?

'Should I break you or should I hang you?'

F. . . you! Ilenssakaci! Kulehkey nayka stress-lul phak phwunceki isseyo.

'(I said) F. . you! You jerk! I released my stress that way.'

Kekise na wenepsi haypwassney. (Studio audiences laughing hard)

'I truly cursed to my heart's content.'

(Seypakwi 'The Quiz Show Changing the World' aired on 5 December 2009)

Junglyul finally gained the upper hand through hybridized verbal transgressions, using both English and Korean swearwords when he went back to the store to complain the following day. The American cashier would be definitely insulted by the English swearwords Junglyul used. Furthermore, the Korean swearwords used by Junglyul contained much stronger and more violent denotations than the English counterparts. The monolingual English speaking cashier had only English to fight with, but the bilingual customer had two languages to fight with. Korean swearwords helped Junglyul 'vent' to his heart's content and his bilingual status provided him with extra explosive verbal ammunition in his linguistic battle, which ultimately gave him the victory of satisfaction. The studio audiences and panelists were uncontrollably laughing while listening to him.

\section{Hybridization as a linguistic necessity}

Linguistic hybridization can occur out of necessity, often motivated by a desire to communicate with foreigners residing in a local community. As of May 2007, over 720,000 foreigners were living in Korea, a 34.7 per cent increase from the previous year (Park 2007). Some of these foreigners, especially those who can speak Korean, appear on 
television as guests and enjoy quasi-celebrity status in the entertainment industry. In addition, some Korean television shows have a segment involving Korean celebrities attempting to communicate with English speaking foreigners. This type of segment is often dubbed 'mission' in recognition of its challenging nature. A weekly dating show called Gold Miss-ka Kanta ('Go Gold Miss!') arranges a blind date for one of the six single women in their mid to late 30 s. In order for them to be selected to go on a date, they need to win a competition which involves some sort of challenge. The title of the show itself contains a noteworthy linguistic innovation. The word gold miss is a 'madein-Korea' English expression, referring to a career driven, financially independent single woman who passed the so-called optimal age of marriage. It is a euphemism for a spinster and a modern rendition of the once widely accepted term old miss in Korea. By replacing 'old' with 'gold' traditionally marginalized single women not in their prime are viewed positively as great catches. Excerpt (8) below features a hybridized interaction between a comedienne named Song Euni and an American single woman discussing her relationship troubles. The American guest has some knowledge of the Korean language and understands and speaks it to a limited degree. Song Euni initiates her conversation in English.

(8) Euni: Because playboy you met? Kyenghemisseyo?

'Do you have experience (with playboys)?'

American guest: Yes, I have.

Enni: When? When?

American guest: Maybe one year ago.

Euni: One year ago? Two leg?

American guest: Of course! Yes, two legs. ${ }^{10}$ (pointing to her own legs)

Euni: Yangtali yessnyakwu?

'Did he cheat on you?

American guest: (looking puzzled)

Euni: Kulenikka one tali she one tali she

(putting one of her legs over a panelist's and the other leg over the American guest's)

'So what I am asking is 'Did he give one leg to her and another leg to her?'

(Did he date two women at the same time?')

American: Got it. (in a realizing tone)

Euni: Okay! (excited)

American guest: I think he had four legs.

Euni: Wow! Really? Four legs? He is octopus (panelists laughing uncontrollably)

(Gold Miss-ka Kanta 'Go Gold Miss!' aired on 3 January 2010)

The term two leg is a direct translation of its Korean counterpart yangtali, which refers to two timing or having an affair. Literally it illustrates legs spread between two lovers. As it is a highly idiomatic expression, the American guest's limited Korean prevents her from understanding what Euni really means and does not understand why Euni asks such an obvious question, namely, 'Does he have two legs?' When Euni realizes that her English is not intelligible to the American guest, she first translates it into Korean and then demonstrates it physically. When the American woman finally understands the non-literal meaning of 'two leg,' she emphasizes her ex-boyfriend's promiscuity by stating that he dated four people at the same time. In response, Euni offers an upgraded version 'octopus,' which elicits hysterical laughter from the panel. 
When linguistic hybridization is utilized with a creative intention, it often serves positive purposes for the speaker. However, for many Koreans English is not always a pleasant tool in their verbal repertoire; rather, it can be an uncomfortable challenge which cannot be avoided. Korean entertainment shows capture and showcase both elements.

\section{CONCLUSION}

Language anxiety about English speaking skills is frequently focalized and viewed as a personal challenge by Korean celebrities but they often transform their linguistic 'complex' into humorous talk. The Korean actors, comedians, and show hosts discussed in this study innovatively sublimate their 'poor' English by diverting its negative energy into a professionally beneficial and socially desired quality - a sense of humor. I argue that their linguistic sublimating effort is a creative appropriation of English language anxiety, which is becoming more intense mainly due to the pressure of globalization (Lee 2013).

In their discussion of an ideal speaker of Japanese English, Moody and Matsumoto (2011) note that what they termed 'language entertainment' television programs are humorous and often discuss common problems Japanese speakers deal with when speaking English. Although the present study does not specifically analyze 'language entertainment' television programs, the fact that Korean celebrities readily talk about English in regular talk shows and variety shows reveals their English-conscious mentality. Using English in Korean humor performed on television is an indication of linguistic attainment as well as linguistic anxiety. It is concurrently associated with linguistic triumph and frustration, both serving and challenging language users and television viewers alike. The coexistence of Korean and English in television entertainment manifests dual sensibilities and attitudinal ambivalence towards linguistic globalization - a skillful display of creative bilingual repertoire and English anxiety connected to the pressure of 'globalize or perish!' Focalizing English language anxiety in Korean humor embodies attitudinal, emotional, and experiential ambivalence about English in globalization-oriented contemporary Korea. The English language in Korea is revered and feared at the same time since English oral skills are strongly desired but hard to master. This attitudinal duality is reconciled and played out on television in the form of linguistic hybridization and this is often achieved by using English in Korean humor.

According to Ross (1998), humor allows people to show their group affinity by including and excluding others. When humor and English are combined, the social stratification impact is quite palpable and hard to ignore. When it comes to English proficiency, characters in Korean television shows are depicted in a polarizing manner-one extreme being the internationally oriented, globetrotting, cosmopolitan, and successful and the other extreme being the undereducated, unsophisticated, and incompetent. Generation-conscious ageism regarding English proficiency typically characterizes senior citizens as sociolinguistic 'underdogs', forcing them to be in a vulnerable position in a family and a society. The respect for the otherwise most experienced and expectedly wisest member of a family is not always forthcoming. Outperforming grandchildren verbally challenge underperforming grandparents and this is mainly due to asymmetric linguistic power-English proficiency. Increasingly more frequent use of English in contemporary Korean entertainment programs poses challenges for those who cannot participate in television culture in any meaningful, successful way as a speaker or hearer. Young Koreans easily understand these new hybridized innovations and readily use them in their personal communication, 
but the same cannot be said about many older viewers because these words are essentially foreign to them.

Verbal humor is enjoyable if you understand it, but it can also isolate people if they do not understand it. Bilingual Korean viewers and humorists understanding English in Korean humor turn their language anxiety into laughter, but monolingual Korean viewers and humorists are likely to continue to struggle with their English language anxiety. The increasing use of English on Korean television and polarized representations of English in entertainment media serve as a gatekeeper distinguishing bilinguals from monolinguals in contemporary Korea. Whether one can be entertained and humored by television programs may become another English-related stratification variable in Korea.

\section{ACKNOWLEDGEMENTS}

I am grateful to two reviewers for their valuable comments. I also thank Dennis Daniels for his helpful stylistic suggestions for the manuscript.

\section{NOTES}

1. This body gesture denotes a tough challenge.

2. This is my translation from Korean.

3. Korean transliteration is in Italics and English expressions are in non-Italics. Translations are presented in single quotes. Direct quotes are indicated by quotations marks in translations too.

4. The term Gold Miss is a euphemism for a spinster, referring to a bachelorette who is normally past the ideal age to marry in Korea (i.e. in their 20s) but is a financially independent, career-driven woman.

5. It means hot in temperature. It does not have a sexual connotation in Korean in this context.

6. She means that he should have said 'Help me!'

7. Hansuk misquotes the doctor who must have said 'Do you mean she has a cold?'

8. He seemed unprepared and somewhat puzzled by her sudden question.

9. The expression 'big eyes' refers not only to the cashier's Western eyes but also refers to the Korean expression 'nwunul pwulalita,' meaning looking with glaring, angry eyes.

10. The American panelist appears puzzled by Euni's comment on 'two legs' because she feels Euni is stating the obvious, that is, humans have two legs, but this is not what Euni means.

\section{REFERENCES}

Alaba, Olugboyega. 1992. Bilingualism as a source of humour in speech usage: The contact between English and Yoruba. Research in Yoruba Language and Literature 2(1).77-85.

Bailey, Phillip, Anthony J. Onwuegbuzie, \& Christine E. Daley. 2000. Correlates of anxiety at three stages of the foreign language learning process. Journal of Language and Social Psychology 19(4).474-490.

Bell, Nancy D. 2007. Safe territory? The humorous narratives of bilingual women. Research on Language and Social Interaction 40(2-3).199-225.

Cheng, Rui, \& Antony Erben. 2012. Language anxiety: Experiences of Chinese graduate students at US higher institutions. Journal of Studies in International Education 16(5).477-497.

Corbett, LaVerne H. 1991. Effect of bilingualism on humor and creativity. Hempstead, NY: Hofstra University dissertation.

Daly, John A. 1991. Understanding communication apprehension: An introduction for language educators. In Elaine

K. Horwitz, \& Dolly J. Young (eds.), Language anxiety: From theory and research to classroom implications, 3-13. Englewood Cliffs, NJ: Prentice-Hall.

Haugen, Einar. 1986. Bilinguals have more fun! Journal of English Linguistics 19(1).106-120.

Holmes, Janet, \& Stephanie Schnurr. 2005. Politeness, humor and gender in the workplace: Negotiating norms and identifying contestation. Journal of Politeness Research 1(1).121-149.

Horwitz, Elaine K., Michael B. Horwitz, \& Joann Cope. 1986. Foreign language classroom anxiety. Modern Language Journal 70(1).125-132.

Jin, Shengxi, \& Bin Wang. 2012. A relevance theoretic-based approach to verbal humor in Joe Wong's talk show. International Journal of English Linguistics 2(3).44-48.

Lee, Jamie S. 2007. Don't know = put some money down = save!: Mock English in Korean comedy. Proceedings of the $8^{\text {th }}$ ISKS International Conference on Korean Studies, Vol. 1, 144-154. London: University of London SOAS. 
Lee, Jamie S. 2009. Segyehwa (Korea's globalization) and English: Women's perspectives. Paper presented at the $15^{\text {th }}$ conference of the International Association for World Englishes, Cebu, Philippines, 23 October.

Lee, Jamie S. 2011. Globalization and language education: English Village in South Korea. Language Research 47(1).123149.

Lee, Jamie S. 2012. Please Teach me English: English and metalinguistic discourse in South Korean film. In Jamie S. Lee \& Andrew Moody (eds.), English in Asian Popular Culture, 127-149. Hong Kong: Hong Kong University Press.

Lee, Jamie S. 2013. Hybridizing medialect and entertaining TV: Korean reality. In Rani Sumant Rubdy \& Rubna Alsagoff (eds.), The global-local interface, language choice and hybridity, 170-188. Bristol: Multilingual Matters.

Lee, Younghee. 2009. 한국 대표배우한국 대표배우아시아가목하는 한류 스타병헌 [A Korean actor and a rising Korean Wave star in Asia Lee Byung Hun]. Joongang Daily, July 30. http://article.joins.com/news/ article/article.asp?total_id=3705600\&cloc (25 May, 2010).

Leeds, Christopher. 1992. Bilingual Anglo-French humor: An analysis of the potential for humor based on the interlocking of the two languages. Humor 5(1/2).129-148.

MacRury, Iain. 2012. Humour as 'social dreaming': Stand-up comedy as therapeutic performance. Psychoanalysis, Culture \& Society 17(2).185-203.

Moody, Andrew, \& Yuko Matsumoto. 2003. Don't touch my moustache: Language blending and code ambiguation by two J-pop artists. Asian Englishes 6(1).4-33.

Moody, Andrew, \& Yuko Matsumoto. 2011. The ideal speaker of Japanese English as portrayed in 'language entertainment' television. In Philip Seargeant (ed.), English in Japan in the era of globalization, 166-186. Basingstoke: Palgrave Macmillan.

Norrick, Neal. 2004. Humor, tellability, and conarration in conversational storytelling. Text 24(1).79-111.

Norrick, Neal R., \& Delia Chiaro (eds.) 2009. Humor in interaction. Amsterdam: Benjamins.

Onwuegbuzie, Anthony J., Phillip Bailey, \& Christine E. Daley. 1999. Factors associated with foreign language anxiety. Applied Psycholinguistics 20(2).217-239.

Park, Joseph S. 2003. 'Baby, Darling, Honey!' Constructing a competence of English in South Korean TV Shows. Texas Linguistic Forum 47(1).143-54.

Park, Joseph S. 2009. The local construction of a global language: Ideologies of English in South Korea. Berlin: Mouton de Gruyter.

Park, Junghyun. 2007. 국 내 거 외 국 만 명! [720, 000 foreigners live in Korea!] News Chosun, August 2. http://m.chosun.com/article.html?contid=2007080200039 (29 May, 2010).

Ross, Alison. 1998. The language of humour. London: Routledge.

Siegel, Jeff. 1995. How to get a laugh in Fijian: Code-switching and humor. Language in Society 24(1).95-110.

Vaid, Jyotsna. 2006. Joking across languages: Perspectives on humor, emotion, and bilingualism. In Aneta Pavlenko (ed.), Bilingual minds: Emotional experience, expression and representation. 152-182. Clevedon: Multilingual Matters.

Zhao, Yan. 1994. Deviation theory for verbal humor: A study in linguistics and beyond. PhD, Purdue University.

(Received 21 June 2013) 